Int. J. Electrochem. Sci., 15 (2020) 6448 - 6463

International Journal of

ELECTROCHEMICAL

SCIENCE

WWW.electrochemsci.org

\title{
Studies on the Wear and Corrosion Resistance of Ni-Fe-Co-P- GO Composite Coating Prepared by Scanning Electrodeposition
}

\author{
Xiu-qing $F u^{1,}{ }^{*}$, Xiao-xin Shi ${ }^{1}$, Shuang-lu Duan ${ }^{1}$, Mo-qi Shen ${ }^{1}$, Jin-ran Lin ${ }^{1}$, Min-Jie Jiang ${ }^{1}$ \\ College of Engineering, Nanjing Agricultural University, Nanjing 210031, P. R. China \\ *E-mail: fuxiuqing@njau.edu.cn
}

doi: $10.20964 / 2020.07 .41$

Received: 14 January 2020 / Accepted: 19 March 2020 / Published: 10 June 2020

In order to improve the problem of unsatisfactory wear and corrosion resistance of traditional materials, a composite coating of Ni-Fe-Co-P-GO is prepared on the surface of $45 \#$ steel by scanning electrodeposition technology. The morphology, composition and phase structures of the Ni-Fe-Co-PGO composite coatings are characterized by scanning electron microscopy (SEM), energy spectrum analysis (EDS) and X-ray diffractometry (XRD). The surface hardness, wear resistance and corrosion resistance of the composite coatings are analyzed by means of a micro hardness tester, a comprehensive tester for surface properties of materials and an electrochemical workstation. The results prove formation of an amorphous Ni-Fe-Co-P-GO composite coating on the surface of 45\# steel. The prepared Ni-FeCo-P-(GO) 0.6 composite coating has maximum surface hardness with best wear and corrosion resistance due to closely connected cell structure on the surface when the concentration of graphene oxide (GO) is $0.6 \mathrm{~g} \cdot \mathrm{L}^{-1}$.

Keywords: Scanning electrodeposition; Ni-Fe-Co-P-GO composite coating; wear resistance; corrosion resistance

\section{$\underline{\text { FULL TEXT }}$}

(C) 2020 The Authors. Published by ESG (www.electrochemsci.org). This article is an open access article distributed under the terms and conditions of the Creative Commons Attribution license (http://creativecommons.org/licenses/by/4.0/). 